\title{
Sex modulates the association of radial artery augmentation index with renal function decline in individuals without chronic kidney disease
}

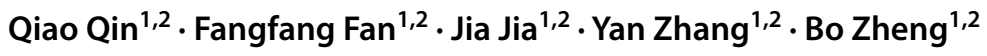

Received: 1 October 2020 / Accepted: 26 December 2020 / Published online: 12 January 2021

(c) The Author(s) 2021

\begin{abstract}
Purpose An increase in arterial stiffness is associated with rapid renal function decline (RFD) in patients with chronic kidney disease (CKD). The aim of this study was to investigate whether the radial augmentation index (rAI), a surrogate marker of arterial stiffness, affects RFD in individuals without CKD.

Methods A total of 3165 Chinese participants from an atherosclerosis cohort with estimated glomerular filtration rates (eGFR) of $\geq 60 \mathrm{~mL} / \mathrm{min} / 1.73 \mathrm{~m}^{2}$ were included in this study. The baseline rAI normalized to a heart rate of 75 beats $/ \mathrm{min}$ (rAIp75) was obtained using an arterial applanation tonometry probe. The eGFRs at both baseline and follow-up were calculated using the equation derived from the Chronic Kidney Disease Epidemiology Collaboration. The association of the rAIp75 with RFD (defined as a drop in the eGFR category accompanied by a $\geq 25 \%$ drop in eGFR from baseline or a sustained decline in eGFR of $>5 \mathrm{~mL} / \mathrm{min} / 1.73 \mathrm{~m}^{2} /$ year) was evaluated using the multivariate regression model.

Results During the 2.35-year follow-up, the incidence of RFD was 7.30\%. The rAIp75 had no statistically independent association with RFD after adjustment for possible confounders (adjusted odds ratio $=1.12,95 \%$ confidence interval: $0.99-1.27$, $p=0.074)$. When stratified according to sex, the rAIp75 was significantly associated with RFD in women, but not in men (adjusted odds ratio and 95\% confidence interval: 1.23[1.06-1.43], $p=0.007$ for women, 0.94[0.76-1.16], $p=0.542$ for men; $p$ for interaction $=0.038$ ).
\end{abstract}

Conclusion The rAI might help screen for those at high risk of early rapid RFD in women without CKD.

Keywords Arterial stiffness $\cdot$ Radial augmentation index $\cdot$ Renal function decline $\cdot$ Sex

\section{Introduction}

Chronic kidney disease (CKD) is increasingly recognized as a global public health problem, which affects $7-12 \%$ of the adult population in different regions of the world. Patients with CKD have a significantly increased risk of death, mainly due to cardiovascular disease that is followed

Yan Zhang

drzhy1108@163.com

Bo Zheng

zhengbopatrick@163.com

1 Department of Cardiology, Institute of Cardiovascular Disease, Peking University First Hospital, No. 8 Xishiku Street, Xicheng District, Beijing 100034, China

2 Institute of Cardiovascular Disease, Peking University First Hospital, Beijing 100034, China by end-stage renal disease $[1,2]$. Therefore, it is crucial to identify those at risk of fast renal function decline (RFD) amongst individuals without CKD as a primary preventive strategy.

Unlike the vascular beds of other organs, renal microcirculation exhibits low impedance and high flow, which make it vulnerable to pulsatile changes in blood flow. With increased arterial stiffness, the cushioning function of the arterial system, which converts the pulsed blood flow from the heart to the continuous blood flow of the capillaries, decreases [3, 4]. Renal microcirculation is exposed to highpressure pulsatility, which may result in glomerular endothelial dysfunction and decreased renal arterial volume [5, 6].

Previous observational studies have provided solid evidence that arterial stiffness is associated with a faster decline in the estimated glomerular filtration rate (eGFR) in CKD patients [7-10]. However, there is no consensus yet on whether an association between arterial stiffness and 
RFD exists in individuals with preserved renal function [5, 11-14].

The radial augmentation index (rAI), a surrogate marker of arterial stiffness, is obtained by an automated tonometer against the radial artery in a seated position $[15,16]$. The rAI is easily measured and is thus considered a suitable marker of arterial stiffness and its association with RFD in a large population with preserved renal function [17]. As the relationship between the $\mathrm{rAI}$ and renal function in individuals without CKD is not well understood, we examined this relationship in a Chinese community population with an eGFR of $\geq 60 \mathrm{~mL} / \mathrm{min} / 1.73 \mathrm{~m}^{2}$.

\section{Methods}

\section{Study population}

We used data from an atherosclerosis cohort from December 2011 to July 2014 in the Gucheng and Pingguoyuan communities of the Shijingshan district in Beijing, China. Detailed study procedures have been described previously [18]. In brief, a baseline survey was collected for 5962 residents aged $\geq 40$ years between December 2011 and April 2012, and $3823(64.1 \%)$ residents returned for a follow-up visit from May to July 2014. The difference in baseline characteristics was not statistically significant between the residents that returned for a follow-up and those that did not. We excluded participants without serum creatinine measurements upon follow-up who already had CKD defined by an eGFR of $<60 \mathrm{~mL} / \mathrm{min} / 1.73 \mathrm{~m}^{2}$ at baseline and who did not have a rAI measurement at baseline. Finally, 3165 participants were included in this study. Informed consent was obtained from all participants, and the study protocol was approved by the ethics committee of Peking University First Hospital.

\section{Data collection}

Baseline data were obtained by trained research staff according to a standard operating procedure. All participants were interviewed using a standardized questionnaire, including demographic characteristics, health behavior, and medical history. Anthropometric measurements were taken according to a standard operating procedure.

After a 5-min rest, seated brachial blood pressure (BP) and pulse measurements were obtained from each participant using an Omron HEM-7117 electronic sphygmomanometer (Omron Health Care, Kyoto, Japan). Triplicate measurements on the right arm were taken with $\geq 1 \mathrm{~min}$ between successive readings. Systolic BP (SBP), diastolic BP (DBP), and pulse were averaged over three consecutive measurements for each participant.
To assess arterial stiffness, the rAI was obtained from the radial arterial waveform by an arterial applanation tonometry probe (HEM-9000AI; Omron Healthcare, Kyoto, Japan). The first and second peaks of brachial systolic pressure (SP1 and SP2) and brachial diastolic pressure were automatically determined using the fourth derivatives for each radial arterial waveform. The rAI was calculated as follows: (SP2-brachial DBP $) /(\mathrm{SP} 1-$ brachial DBP $) \times 100(\%)$. Since the $\mathrm{rAI}$ is influenced by heart rate, it was normalized to 75 beats/min (rAIp75) according to previous guidelines [19].

Venous blood samples were obtained from the forearm of participants that had fasted overnight. Fasting blood glucose, $2 \mathrm{~h}$ glucose concentration in the standard $75 \mathrm{~g}$ oral glucose tolerance test, total cholesterol, low-density lipoprotein cholesterol, high-density lipoprotein cholesterol, and triglyceride concentrations were measured using a Roche C8000 Automatic Analyzer. As described previously [18], serum creatinine concentration at baseline and followup were analyzed using the enzymatic method and Jaffe's kinetic method, respectively, in different laboratory centers. To ensure comparability, the serum creatinine concentrations at baseline and follow-up were transformed into values by the enzymatic method and finally calibrated to the values of one core laboratory. The eGFR was calculated using the equation published by the Chronic Kidney Disease Epidemiology Collaboration [20].

\section{Outcome}

The outcome assessed in this study was RFD during the follow-up period, defined according to the Kidney Disease: Improving Global Outcome 2012 definition as follows: a drop in the GFR category ( $\geq 90$ [G1]), 60-89 [G2], 45-59 [G3a], 30-44 [G3b], 15-29 [G4], and < 15 [G5] mL/ $\mathrm{min} / 1.73 \mathrm{~m}^{2}$ ) accompanied by a $\geq 25 \%$ drop in eGFR from baseline or a sustained decline in eGFR of $>5 \mathrm{~mL} / \mathrm{min} / 1.73$ $\mathrm{m}^{2} /$ year [21].

\section{Definitions}

Current smoking was defined as smoking at least one cigarette per day for at least half a year. Current drinking was defined as drinking alcohol at least once per week for at least half a year. Body mass index (BMI) was calculated as weight in kilograms divided by the square of height in meters. Hypertension at baseline was defined as any selfreported history of hypertension, or a $\mathrm{SBP} \geq 140 \mathrm{mmHg}$ or $\mathrm{DBP} \geq 90 \mathrm{mmHg}$, or prescribed antihypertensive drugs. Diabetes mellitus at baseline was defined as any selfreported history of diabetes, fasting blood glucose levels $\geq 7.0 \mathrm{mmol} / \mathrm{L}$, oral glucose tolerance test $\geq 11.1 \mathrm{mmol} / \mathrm{L}$, or prescribed hypoglycemic drugs. Dyslipidemia at baseline was defined as any self-reported history of 
hyperlipidemia, total cholesterol levels $\geq 5.18 \mathrm{mmol} / \mathrm{L}$ (200 mg/dL), low-density lipoprotein cholesterol levels $>3.37 \mathrm{mmol} / \mathrm{L}(130 \mathrm{mg} / \mathrm{dL})$, high-density lipoprotein cholesterol levels $<1.04 \mathrm{mmol} / \mathrm{L}$ ( $40 \mathrm{mg} / \mathrm{dL})$, triglyceride levels $\geq 1.70 \mathrm{mmol} / \mathrm{L}$ ( $150 \mathrm{mg} / \mathrm{dL}$ ), or prescribed lipid-lowering medications. Cardiovascular disease at baseline was defined as any self-reported history of coronary heart disease, stroke, or transient ischemic attack.

\section{Statistical analysis}

Data are expressed as mean \pm standard deviation [SD] for normally distributed variables. The differences in values between baseline characteristics were assessed using ANOVA for continuous variables and the Pearson's $\chi 2$ test for categorical variables. Restrictive cubic splines were used to visualize the relationship rAIp75 and RFD, and then logistic regression analysis were performed to observe the effects of baseline rAIp75 on RFD after adjustment for age, sex, BMI, baseline eGFR, current smoking status, current drinking status, medical history (hypertension) as well as the usage of antihypertensive, hypoglycemic, and lipid-lowering drugs. Subgroup and interaction analysis was performed with regard to sex. A $P$ value of $<0.05$ (two-sided) was considered statistically significant for all tests. All analyses were performed using Empower(R) (www.empowersta ts.com, X\&Y Solutions, Inc. Boston MA) and R (http:// www.R-project.org).

\section{Results}

Table 1 shows the characteristics of the participants overall and stratified by tertiles of baseline rAIp75. The mean (SD) age of the participants was $56.64 \pm 8.48$ years, and $64.01 \%(2026 / 3165)$ of the participants were female. The prevalence of hypertension and diabetes mellitus was $49.23 \%(1558 / 3165)$ and $23.54 \%(745 / 3165)$, respectively. rAIp75 was $80.49 \pm 11.96 \%$. The baseline eGFR was $101.18 \pm 10.63 \mathrm{~mL} / \mathrm{min} / 1.73 \mathrm{~m}^{2}$ and the follow-up eGFR was $98.36 \pm 11.91 \mathrm{~mL} / \mathrm{min} / 1.73 \mathrm{~m}^{2}$. Participants with higher rAIp75 were more likely to be female and had a significantly lower BMI, pulse, and prevalence of current smoking and drinking. Neither the prevalence of hypertension, diabetes mellitus, dyslipidemia, or cardiovascular disease nor the usage of antihypertensive, hypoglycemic, or lipid-lowering drugs significantly differed between participants with different rAIp75 levels.

After a mean 2.35-year follow-up, the incidence of RFD was 7.30\%. Smooth curve fitting (Fig. 1a) and logistic regression analysis (Table 2) were conducted to assess the association between the rAIp75 and RFD. The smooth curve fitting presented that elevated rAI was related to the

Table 1 Characteristics of participants stratified by baseline rAIp75

\begin{tabular}{|c|c|c|c|c|c|}
\hline \multirow[t]{2}{*}{ Variables } & \multirow[t]{2}{*}{ Total } & \multicolumn{3}{|l|}{ rAIp75, \% } & \multirow[t]{2}{*}{$p$} \\
\hline & & Tertile $1(37-75)$ & Tertile 2 (76-84) & Tertile $3(85-142)$ & \\
\hline$N$ & 3165 & 1021 & 1020 & 1124 & \\
\hline Age, years & $56.64 \pm 8.48$ & $55.85 \pm 8.18$ & $57.39 \pm 8.63$ & $56.67 \pm 8.53$ & $<0.001$ \\
\hline Female, $n(\%)$ & $2026(64.01 \%)$ & $396(38.79 \%)$ & $698(68.43 \%)$ & $932(82.92 \%)$ & $<0.001$ \\
\hline BMI, $\mathrm{kg} / \mathrm{m}^{2}$ & $26.03 \pm 3.36$ & $26.30 \pm 3.35$ & $26.04 \pm 3.46$ & $25.77 \pm 3.25$ & 0.001 \\
\hline Pulse, beats/min & $76.15 \pm 11.75$ & $77.37 \pm 12.41$ & $75.76 \pm 11.31$ & $75.40 \pm 11.44$ & $<0.001$ \\
\hline rAIp $75, \%$ & $80.49 \pm 11.96$ & $67.51 \pm 6.87$ & $80.17 \pm 2.55$ & $92.56 \pm 7.40$ & $<0.001$ \\
\hline Baseline eGFR, $\mathrm{mL} / \mathrm{min} / 1.73 \mathrm{~m}^{2}$ & $101.18 \pm 10.63$ & $101.21 \pm 10.98$ & $100.50 \pm 10.52$ & $101.77 \pm 10.39$ & 0.023 \\
\hline Follow-up eGFR, $\mathrm{mL} / \mathrm{min} / 1.73 \mathrm{~m}^{2}$ & $98.36 \pm 11.91$ & $99.03 \pm 12.55$ & $97.80 \pm 11.06$ & $98.25 \pm 12.04$ & 0.062 \\
\hline Current smoking, $n(\%)$ & $588(18.58 \%)$ & $292(28.60 \%)$ & $156(15.29 \%)$ & $140(12.46 \%)$ & $<0.001$ \\
\hline Current alcohol intake, $n(\%)$ & $729(23.03 \%)$ & $361(35.36 \%)$ & $195(19.12 \%)$ & $173(15.39 \%)$ & $<0.001$ \\
\hline \multicolumn{6}{|l|}{ Prevalence of disease } \\
\hline Hypertension, $n(\%)$ & $1558(49.23 \%)$ & $517(50.64 \%)$ & $510(50.00 \%)$ & $531(47.24 \%)$ & 0.243 \\
\hline Diabetes mellitus, $n(\%)$ & $745(23.54 \%)$ & $244(23.90 \%)$ & $235(23.04 \%)$ & $266(23.67 \%)$ & 0.894 \\
\hline Dyslipidemia, $n(\%)$ & $2256(71.28 \%)$ & $727(71.20 \%)$ & $702(68.82 \%)$ & $827(73.58 \%)$ & 0.052 \\
\hline Self-reported cardiovascular disease, $n(\%)$ & $391(12.35 \%)$ & $138(13.52 \%)$ & $122(11.96 \%)$ & $131(11.65 \%)$ & 0.382 \\
\hline \multicolumn{6}{|l|}{ Medication } \\
\hline Antihypertensive medications & $982(31.20 \%)$ & $329(32.29 \%)$ & $324(32.14 \%)$ & $329(29.38 \%)$ & 0.257 \\
\hline Hypoglycemic medications & $310(9.83 \%)$ & $96(9.42 \%)$ & $108(10.66 \%)$ & $106(9.44 \%)$ & 0.555 \\
\hline Lipid-lowering medications & $327(10.44 \%)$ & $104(10.27 \%)$ & $116(11.54 \%)$ & $107(9.60 \%)$ & 0.335 \\
\hline
\end{tabular}

$B M I$ body mass index, $e G F R$ estimated glomerular filtration rate, $r A I p 75$ radial augmentation index per 75 heart beats 


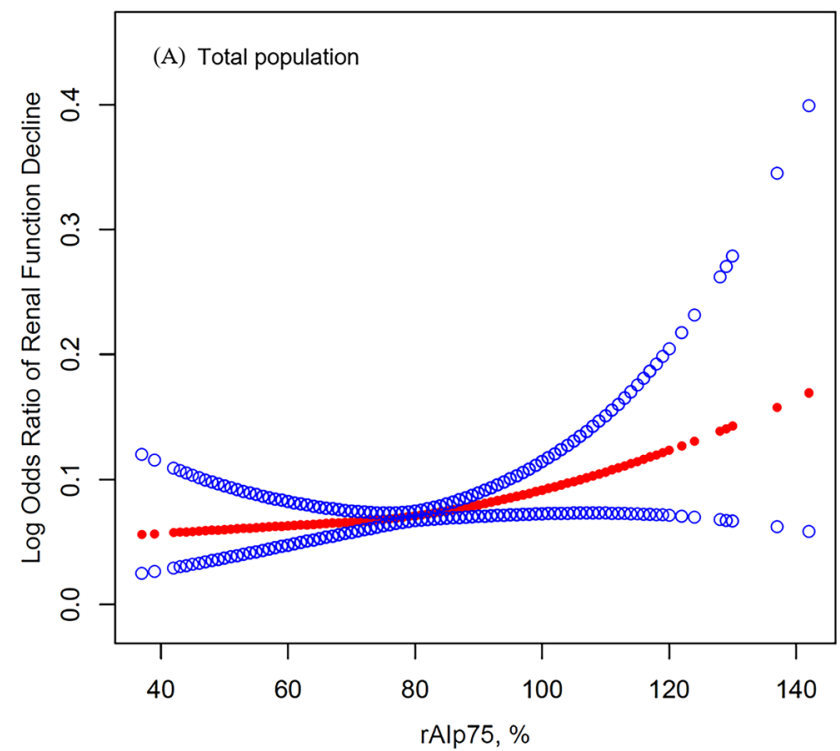

Fig. 1 Smooth curve fitting of the rAIp75 and RFD in total population (a) and in subgroup stratified by sex (b). Variables in the model: age, sex, body mass index, baseline eGFR, current smoking status, current drinking status, hypertension, diabetes mellitus, dyslipidemia,

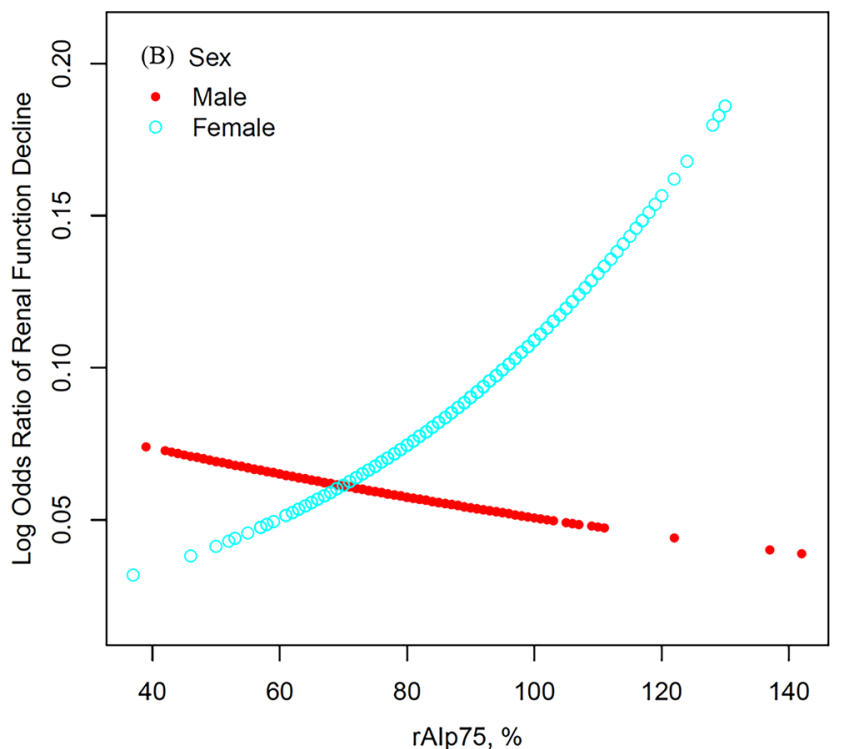

self-reported cardiovascular disease, antihypertensive medications, hypoglycemic medications, and lipid-lowering medications. rAIp75 radial augmentation index per 75 heart beats
Table 2 Multivariate regression analysis of the effect of the rAIp75 on RFD

\begin{tabular}{|c|c|c|c|c|c|c|}
\hline \multirow[t]{2}{*}{ Variable } & \multicolumn{2}{|c|}{ Crude model $(N=3165)$} & \multicolumn{2}{|l|}{$\begin{array}{l}\text { Adjusted model } 1 \\
(N=3165)\end{array}$} & \multicolumn{2}{|l|}{$\begin{array}{l}\text { Adjusted model } 2 \\
(N=3121)\end{array}$} \\
\hline & OR $(95 \% \mathrm{CI})$ & $p$ & OR $(95 \% \mathrm{CI})$ & $p$ & OR $(95 \% \mathrm{CI})$ & $p$ \\
\hline rAIp75, per $10 \%$ increase & $1.17(1.05,1.31)$ & 0.005 & $1.12(1.00,1.27)$ & 0.058 & $1.12(0.99,1.27)$ & 0.074 \\
\hline \multicolumn{7}{|l|}{ rAIp75 categories } \\
\hline $\mathrm{T} 1(37-75)$ & 1 & & 1 & & 1 & \\
\hline $\mathrm{T} 2(76-84)$ & $1.05(0.74,1.50)$ & 0.782 & $0.94(0.65,1.36)$ & 0.737 & $0.94(0.65,1.37)$ & 0.745 \\
\hline T3 (85-142) & $1.46(1.05,2.02)$ & 0.023 & $1.26(0.89,1.80)$ & 0.195 & $1.26(0.88,1.81)$ & 0.204 \\
\hline$p$ for trend & & 0.018 & & 0.144 & & 0.154 \\
\hline
\end{tabular}

Adjusted Model 1: adjusted for age and sex

Adjusted Model 2: adjusted for: age, sex, body mass index, baseline estimated glomerular filtration rate, current smoking status, current drinking status, hypertension, diabetes mellitus, dyslipidemia, self-reported cardiovascular disease, antihypertensive medications, hypoglycemic medications, and lipid-lowering medications

$O R$ odds ratio, rAIp75 radial augmentation index per 75 heart beats, $R F D$ renal function decline, $C I$ confidence interval increased prevalence of RFD in general population. In the crude models, rAIp75 was significantly associated with RFD (odds ratio $[\mathrm{OR}]=1.17,95 \%$ confidence interval $[\mathrm{CI}]$ : $1.05-1.31, p=0.005)$. However, the association did not persist after adjustment for possible confounders $(\mathrm{OR}=1.12$, 95\% CI: 0.99-1.27, $p=0.074)$.

As shown in Table 3, the effect of baseline rAIp75 on RFD was modified by sex ( $\mathrm{p}$ for interaction $=0.038$ ). The relationship between rAIp75 and RFD was observed in women $(\mathrm{OR}=1.23,95 \% \mathrm{CI}: 1.06-1.43, p=0.007)$, but not in men $(\mathrm{OR}=0.94,95 \% \mathrm{CI}: 0.76-1.16, p=0.542)$. The
Table 3 Interactive effect between sex and the rAIp75 on RFD

\begin{tabular}{lllll}
\hline Sex & RFD, $n(\%)$ & OR $(95 \%$ CI $)$ & $p$ & $p$ for interaction \\
\hline Male & $67(5.9 \%)$ & $0.94(0.76,1.16)$ & 0.5420 & $\mathbf{0 . 0 3 8}$ \\
Female & $164(8.1 \%)$ & $1.23(1.06,1.43)$ & 0.0074 & \\
\hline
\end{tabular}

Variables in the model: age, sex, body mass index, baseline eGFR, current smoking status, current drinking status, hypertension, diabetes mellitus, dyslipidemia, self-reported cardiovascular disease, antihypertensive medications, hypoglycemic medications, and lipid-lowering medications

$C I$ confidence interval, $O R$ odds ratio, rAIp75 radial augmentation index per 75 heart beats, $R F D$ renal function decline 
trends in the two subgroups shown by smooth curves in Fig. $1 \mathrm{~b}$ were consistent with the analysis above.

\section{Discussion}

In this Chinese community-based study of 3165 participants with an eGFR of $\geq 60 \mathrm{~mL} / \mathrm{min} / 1.73 \mathrm{~m}^{2}$, the $\mathrm{rAI}$, an indicator of arterial stiffness, was not independently associated with RFD. However, we found that the association between rAI and RFD was modulated by sex. Namely, the rAI was significantly associated with RFD in women, but not in men.

The kidney is a specific high-flow and low-resistance end organ, which renders it more vulnerable than other organs to systemic pulsatile damage in the presence of increased arterial stiffness [6, 22]. Data from Age, Gene/Environment Susceptibility-Reykjavik Study (AGES-RS) included 367 elderly adults with an average GFR of $65 \mathrm{~mL} / \mathrm{min} / 1.73 \mathrm{~m}^{2}$ and showed an association between arterial stiffness and GFR (slope of regression $\beta=-2.28 \pm 0.85 \mathrm{~mL} / \mathrm{min}$ per $\mathrm{SD}, p=0.008)$; however, the relation was no longer significant $(p=0.10)$ after taking into account the pulsatility index. Mediation analysis revealed that $34 \%$ of the association between aortic stiffness and GFR was mediated by the pulsatility index (95\% CI of indirect effect: 21.35-20.29), indicating that the relation between aortic stiffness and lower GFR may be mediated by the transmission of excessive pulsatility to the renal microvasculature [6]. The rAI, derived from the pressure waveform resulting from applanation tonometry that applies slight pressure on the radial artery, is considered a useful and easily obtainable marker of arterial stiffness $[17,23]$. Studies have demonstrated that the rAI is associated with a rapid deterioration of renal function in patients with moderately to severely decreased renal function $[10,24,25]$. A study by Weber et al., including patients with stage 3-4 CKD, demonstrated that each $10 \%$ increase in rAI was associated with a $47 \%$ increased risk of reaching the combined renal endpoint of doubling serum creatinine or of requiring dialysis or transplantation ( $\mathrm{HR}=1.474,95 \%$ CI: 1.020-2.030) [10]. Similarly, Taal et al. [25] reported that the rAI was an independent risk factor for end-stage renal disease in patients with CKD stages $4-5(\mathrm{HR}=1.08$, 95\% CI: 1.04-1.14).

However, to the best of our knowledge, only two prospective studies have examined the relationship between the rAI and RFD in patients with preserved renal function [26, 27]. Data on a multiethnic cohort including 5232 participants in the US showed that the rAI by tertile was not related to rapid RFD (defined as an annual eGFR loss of $>3 \mathrm{~mL} / \mathrm{min} / 1.73$ $\left.\mathrm{m}^{2}\right)$ during a 5-year period ( $\mathrm{OR}=0.98,95 \% \mathrm{CI}$ : $\left.0.82-1.16\right)$ [26]. Similarly, a longitudinal analysis from a communitybased cohort of 948 participants that were followed up for 5 years in China revealed that the rAI had no statistically independent association with any rapid RFD (defined as an annual GFR loss of $\left.>3 \mathrm{~mL} / \mathrm{min} / 1.73 \mathrm{~m}^{2}\right)(\mathrm{HR}=0.994,95 \%$ CI: 0.974-1.015) [27]. The present study is by far the largest study in China to explore the relationship between the rAI and RFD in a non-CKD population. Unlike previous studies, RFD was defined by the standard of the Kidney Disease: Improving Global Outcome in this study [21]. More importantly, although we did not find an independent correlation between the rAI and RFD in the overall population, further subgroup analysis revealed this correlation in women group. This finding suggests that female may be a factor that enhances the effect of rAI on RFD. However, it is still unclear how sex modifies the relationship between rAI and RFD, and thus further studies are needed.

Several limitations to our study should be acknowledged. First, the sample size of our study was relatively small, and the follow-up period was not long enough. Second, serum creatinine at baseline and follow-up was measured in different methods in different laboratories, which may lead to some deviations. However, these creatinine results were transformed into values measured by enzymatic method and calibrated to the values of the third laboratory. Third, the eGFR decline endpoints were based on measurements acquired at only two time points; this most likely reduces the accuracy of our assessment. Fourth, participants in this Beijing community-based study were recruited by responding to recruitment posters or invited phone calls instead of using random sampling method; this might contribute to sampling bias to some extent. Finally, only Chinese participants were included in our study, which limits the generalizability of our findings to other populations.

\section{Conclusions}

This study, conducted on a Chinese community-based population with an eGFR of $\geq 60 \mathrm{~mL} / \mathrm{min} / \mathrm{m}^{2}$, identified an association between increased arterial stiffness and RFD in women. The rAI might represent a suitable measurement for large-scale populations and may facilitate the identification of individuals at high risk of RFD.

Acknowledgements We thank all the authors for their cooperation and the implementation of this study. We are also grateful for the organization implemented by site managers Dr. Shuyu Wang and Dr. Liguang Dong.

Author contributions $\mathrm{YZ}$ and $\mathrm{BZ}$ had full access to all the data in the study and take responsibility for the integrity of the data and the accuracy of the data analysis. Study concept and design: YZ, BZ, and FF. Conduct of study: YZ, BZ, FF, QQ, and JJ. Data management and statistical analysis: FF. Drafting of the manuscript: QQ. Review and revision of the article: YZ, BZ, FF, and JJ. The final manuscript has been reviewed and approved by all the authors. 
Funding This work was supported by the Key Laboratory of Molecular Cardiovascular Sciences (Peking University), Ministry of Education and NHC Key Laboratory of Cardiovascular Molecular Biology and Regulatory Peptides; the University of Michigan-Peking University Health Science Centre (UMHS-PUHSC) Joint Institute for Translational and Clinical Research and the Fundamental Research Funds for the Central Universities (Grant no. BMU20110177 and BMU20160530); and the National Key Research and Development Program of China (Grant no. 2017YFC1307704).

\section{Compliance with ethical standards}

Conflict of interest The authors declare that there is no conflict of interest.

Ethics approval Informed consent was obtained from all participants, and the study protocol was approved by the ethics committee of Peking University First Hospital.

Informed consent Informed consent was obtained from all individual participants included in the study. Consent to publish: patients signed informed consent regarding publishing their data.

Open Access This article is licensed under a Creative Commons Attribution 4.0 International License, which permits use, sharing, adaptation, distribution and reproduction in any medium or format, as long as you give appropriate credit to the original author(s) and the source, provide a link to the Creative Commons licence, and indicate if changes were made. The images or other third party material in this article are included in the article's Creative Commons licence, unless indicated otherwise in a credit line to the material. If material is not included in the article's Creative Commons licence and your intended use is not permitted by statutory regulation or exceeds the permitted use, you will need to obtain permission directly from the copyright holder. To view a copy of this licence, visit http://creativecommons.org/licenses/by/4.0/.

\section{References}

1. Jha V, Garcia-Garcia G, Iseki K, Li Z, Naicker S, Plattner B, Saran R, Wang AY, Yang CW (2013) Chronic kidney disease: global dimension and perspectives. Lancet 382(9888):260-272. https:// doi.org/10.1016/S0140-6736(13)60687-X

2. Romagnani P, Remuzzi G, Glassock R, Levin A, Jager KJ, Tonelli M, Massy Z, Wanner C, Anders HJ (2017) Chronic kidney disease. Nat Rev Dis Primers 3:17088. https://doi.org/10.1038/ nrdp. 2017.88

3. Townsend RR, Tomiyama H (2013) Arterial stiffness, kidney function, and chronic kidney disease progression. Pulse 1(2):123 130. https://doi.org/10.1159/000354113

4. Garnier A, Briet M (2016) Arterial stiffness and chronic kidney disease. Pulse 3(3-4):229-241. https://doi.org/10.1159/00044 3616

5. Sedaghat S, Mattace-Raso FUS, Hoorn EJ, Uitterlinden AG, Hofman A, Ikram MA, Franco OH, Dehghan A (2015) Arterial stiffness and decline in kidney function. Clin J Am Soc Nephro 10(12):2190-2197. https://doi.org/10.2215/CJN.03000315

6. Woodard T, Sigurdsson S, Gotal JD, Torjesen AA, Inker LA, Aspelund T, Eiriksdottir G, Gudnason V, Harris TB, Launer LJ, Levey AS, Mitchell GF (2015) Mediation analysis of aortic stiffness and renal microvascular function. J Am Soc Nephrol 26(5):1181-1187. https://doi.org/10.1681/ASN.2014050450
7. Ford ML, Tomlinson LA, Chapman TP, Rajkumar C, Holt SG (2010) Aortic stiffness is independently associated with rate of renal function decline in chronic kidney disease stages 3 and 4 . Hypertension 55(5):1110-1115. https://doi.org/10.1161/HYPER TENSIONAHA.109.143024

8. Chen SC, Chang JM, Liu WC, Tsai YC, Tsai JC, Hsu PC, Lin TH, Lin MY, Su HM, Hwang SJ, Chen HC (2011) Brachial-ankle pulse wave velocity and rate of renal function decline and mortality in chronic kidney disease. Clin J Am Soc Nephrol 6(4):724732. https://doi.org/10.2215/CJN.07700910

9. Chen SC, Chang JM, Tsai YC, Su HM, Chen HC (2012) Brachial-ankle pulse wave velocity and brachial pre-ejection period to ejection time ratio with renal outcomes in chronic kidney disease. Hypertens Res 35(12):1159-1163. https://doi.org/10.1038/ hr.2012.114

10. Weber T, Ammer M, Gunduz D, Bruckenberger P, Eber B, Wallner M (2011) Association of increased arterial wave reflections with decline in renal function in chronic kidney disease stages 3 and 4. Am J Hypertens 24(7):762-769. https://doi.org/10.1038/ ajh.2011.45

11. Upadhyay A, Hwang SJ, Mitchell GF, Vasan RS, Vita JA, Stantchev PI, Meigs JB, Larson MG, Levy D, Benjamin EJ, Fox CS (2009) Arterial stiffness in mild-to-moderate CKD. J Am Soc Nephrol 20(9):2044-2053. https://doi.org/10.1681/ASN.20090 10074

12. Bouchi R, Babazono T, Mugishima M, Yoshida N, Nyumura I, Toya K, Hanai K, Tanaka N, Ishii A, Uchigata Y, Iwamoto Y (2011) Arterial stiffness is associated with incident albuminuria and decreased glomerular filtration rate in type 2 diabetic patients. Diabetes Care 34(12):2570-2575. https://doi.org/10.2337/ dc11-1020

13. Peralta CA, Jacobs DRJ, Katz R, Ix JH, Madero M, Duprez DA, Sarnak MJ, Criqui MH, Kramer HJ, Palmas W, Herrington D, Shlipak MG (2012) Association of pulse pressure, arterial elasticity, and endothelial function with kidney function decline among adults with estimated GFR $>60 \mathrm{~mL} / \mathrm{min} / 1.73 \mathrm{~m}(2)$ : the Multi-Ethnic Study of Atherosclerosis (MESA). Am J Kidney Dis 59(1):41-49. https://doi.org/10.1053/j.ajkd.2011.08.015

14. Madero M, Peralta C, Katz R, Canada R, Fried L, Najjar S, Shlipak M, Simonsick E, Lakatta E, Patel K, Rifkin D, Hawkins M, Newman A, Sarnak M, Health AS (2013) Association of arterial rigidity with incident kidney disease and kidney function decline: the Health ABC study. Clin J Am Soc Nephro 8(3):424-433. https ://doi.org/10.2215/CJN.07900812

15. Nichols WW (2005) Clinical measurement of arterial stiffness obtained from noninvasive pressure waveforms. Am J Hypertens 18(1 Pt 2):3S-10S. https://doi.org/10.1016/j.amjhy per.2004.10.009

16. Sako H, Miura S, Kumagai K, Saku K (2009) Associations between augmentation index and severity of atheroma or aortic stiffness of the descending thoracic aorta by transesophageal echocardiography. Circ J 73(6):1151-1156. https://doi.org/10.1253/ circj.cj-08-0404

17. Kohara K, Tabara Y, Oshiumi A, Miyawaki Y, Kobayashi T, Miki T (2005) Radial augmentation index: a useful and easily obtainable parameter for vascular aging. Am J Hypertens $18(1 \mathrm{Pt}$ 2):11S-14S. https://doi.org/10.1016/j.amjhyper.2004.10.010

18. Fan F, Qi L, Jia J, Xu X, Liu Y, Yang Y, Qin X, Li J, Li H, Zhang Y, Huo Y (2016) Noninvasive central systolic blood pressure is more strongly related to kidney function decline than peripheral systolic blood pressure in a Chinese community-based population. Hypertension 67(6):1166-1172. https://doi.org/10.1161/HYPER TENSIONAHA.115.07019

19. Wilkinson IB, MacCallum H, Flint L, Cockcroft JR, Newby DE, Webb DJ (2000) The influence of heart rate on augmentation index 
and central arterial pressure in humans. J Physiol 525(1):263-270. https://doi.org/10.1111/j.1469-7793.2000.t01-1-00263.x

20. Levey AS, Stevens LA, Schmid CH, Zhang YL, Castro AR, Feldman HI, Kusek JW, Eggers P, Van Lente F, Greene T, Coresh J (2009) A new equation to estimate glomerular filtration rate. Ann Intern Med 150(9):604-612. https://doi.org/10.7326/0003-4819150-9-200905050-00006

21. International Society of Nephrology (2013) Chapter 2: definition, identification, and prediction of CKD progression. Kidney Int Suppl 3(1):63-72. https://doi.org/10.1038/kisup.2012.65

22. O'Rourke MF, Safar ME (2005) Relationship between aortic stiffening and microvascular disease in brain and kidney: cause and logic of therapy. Hypertension 46(1):200-204. https://doi. org/10.1161/01.HYP.0000168052.00426.65

23. Laurent S, Cockcroft J, Van Bortel L, Boutouyrie P, Giannattasio C, Hayoz D, Pannier B, Vlachopoulos C, Wilkinson I, StruijkerBoudier H (2006) Expert consensus document on arterial stiffness: methodological issues and clinical applications. Eur Heart J 27(21):2588-2605. https://doi.org/10.1093/eurheartj/ehl254

24. Takenaka T, Mimura T, Kanno Y, Suzuki H (2005) Qualification of arterial stiffness as a risk factor to the progression of chronic kidney diseases. Am J Nephrol 25(5):417-424. https:// doi.org/10.1159/000087605
25. Taal MW, Sigrist MK, Fakis A, Fluck RJ, McIntyre CW (2007) Markers of arterial stiffness are risk factors for progression to endstage renal disease among patients with chronic kidney disease stages 4 and 5. Nephron Clin Pract 107(4):c177-c181. https://doi. org/10.1159/000110678

26. Hsu JJ, Katz R, Chirinos JA, Jacobs DJ, Duprez DA, Peralta CA (2016) Arterial wave reflections and kidney function decline among persons with preserved estimated glomerular filtration rate: the Multi-Ethnic Study of Atherosclerosis. J Am Soc Hypertens 10(5):438-446. https://doi.org/10.1016/j.jash.2016.02.014

27. Fu S, Liu C, Luo L, Ye P (2017) Predictive abilities of cardiovascular biomarkers to rapid decline of renal function in Chinese community-dwelling population: a 5-year prospective analysis. BMC Nephrol 18(1):331. https://doi.org/10.1186/s1288 2-017-0743-y

Publisher's Note Springer Nature remains neutral with regard to jurisdictional claims in published maps and institutional affiliations. 